\title{
The natural history of a non-stenotic bicuspid aortic valve $^{1}$
}

\author{
PETER MILLS, GRAHAM LEECH, MICHAEL DAVIES, AND AUBREY LEATHAM \\ From the Cardiac Department, St George's Hospital, Hyde Park Corner, London
}

SUMMARY Forty-one patients in whom the diagnosis of a non-stenotic bicuspid aortic valve had been established by noninvasive techniques were followed up for a mean of 10.9 years. During this period, 2 patients required aortic valve replacement because of the development of calcific aortic valve stenosis at the ages of 52 and 64 and 5 others developed evidence of mild aortic valve stenosis. The appearance of calcium in a bicuspid aortic valve suggests the possibility of subsequent calcific aortic stenosis, and patients with this feature should be carefully followed up.

Bacterial endocarditis on the aortic valve occurred in 3 patients, one of whom developed severe aortic regurgitation and subsequently died. Patients with a bicuspid aortic valve are at definite risk from bacterial endocarditis and should receive appropriate antibiotic prophylaxis. In 26/41 (63\%) patients there was no clinical change during the follow-up period, including 7 of the patients over the age of 50 .

Over 400 years ago, Leonardo da Vinci sketched aortic valves with 2,3 , and 4 cusps. He concluded that the optimal relation between structure and function would be provided by a valve with 3 cusps. Osler (1886), however, found that a bicuspid aortic valve may be encountered as an incidental finding at necropsy and the fact that such a valve may still be functioning normally in the seventh and eighth decades of life has been subsequently confirmed (Wauchope, 1928; Edwards, 1961; Roberts, 1970; Pomerance and Davies, 1975; Fenoglio et al., 1977). On the other hand, a bicuspid aortic valve may be the site of infective endocarditis or calcific aortic stenosis. Osler's interest in bicuspid aortic valves was stimulated by his finding of bacterial endocarditis on such a valve and the importance of this was emphasised by Lewis and Grant (1923). Calcific aortic stenosis occurring in a bicuspid aortic valve was first recognised by Peacock in 1868, but despite this observation, it was generally thought that isolated calcific aortic stenosis occurring in adults was the result of rheumatic valvular disease (Karsner and Koletsky, 1947). Because of the frequent history in these patients of a murmur since infancy, Campbell and Kauntze (1953) suggested that there might be an underlying congenital abnormality and in 1959 Bacon and Matthews

1 Presented to the British Cardiac Society in April 1975.

Received for publication 19 October 1977 showed that in many cases of isolated calcific aortic stenosis, the aortic valve was bicuspid.

Although a bicuspid aortic valve is the commonest congenital anomaly of the heart (Wauchope, 1928), the incidence of the complications of infection and stenosis will remain unknown until the presence of the abnormality can be detected during life (Bacon and Matthews, 1959). Evidence has now accumulated to indicate that an isolated aortic ejection sound, identified by its relation to aortic valve movement, and confirmed by the echocardiographic appearance of the valve, is an accurate indication of the presence of a non-stenotic bicuspid aortic valve (Leech et al., 1978). Since 1950, otherwise normal subjects thought to have an isolated aortic ejection sound have been indexed and this study presents the results of follow-up of these patients, the survivors being re-examined by one of us and investigated by echophonocardiography.

\section{Patients and methods}

\section{PATIENTS}

Since 1950, 54 subjects with an early systolic sound, thought to be an aortic ejection sound, documented by phonocardiography and carotid pulse tracings, have been indexed and form the basis of the present study, None of the patients had evidence of aortic stenosis or regurgitation when first seen. The original electrocardiogram and chest $x$-ray film were normal apart from slight prominence of the ascending aorta in some cases 


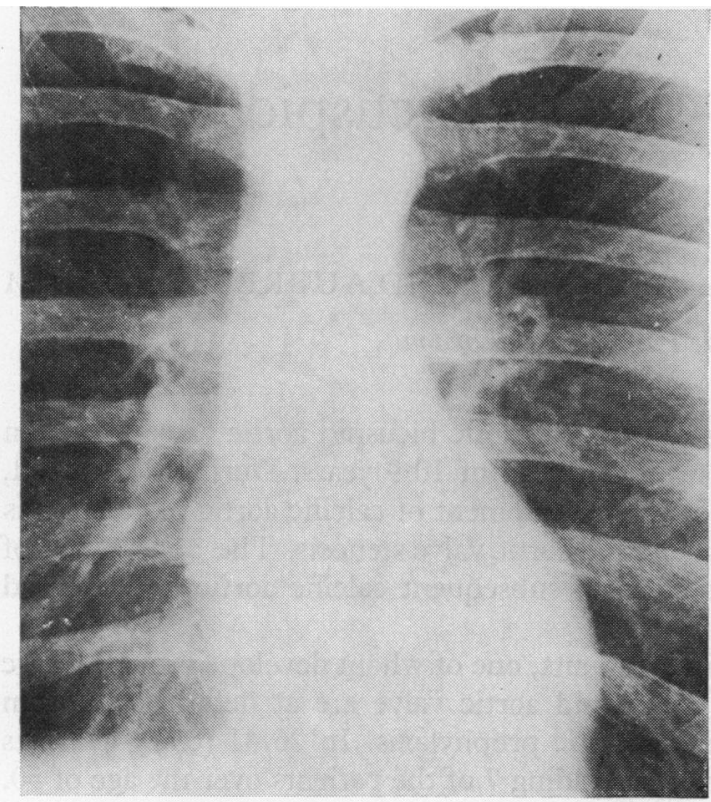

Fig. 1 Chest $\mathrm{x}$-ray of case 24 who has no signs of deterioration after 14 years follow-up, showing slight prominence of the border of the ascending aorta, typical of a non-stenotic bicuspid aortic valve.

(Fig. 1). A minimal follow-up period of 5 years was required for inclusion in the study.

\section{DEFINITION OF STUDY GROUP}

Review of the original phonocardiograms showed that in 6 , either the carotid upstroke or the left ventricular ejection time marginally exceeded normal limits (Bonner et al., 1973). This suggested that a minimal degree of stenosis may have been present, though the systolic murmur was soft enough to have been physiological, the carotid pulse felt normal, and there was no clinical or electrocardiographic evidence of left ventricular hypertrophy. In a further 7 patients, the echophonocardiogram disclosed that the original diagnosis of an aortic ejection sound was incorrect and this was usually caused by confusion with a loud late tricuspid component of the first heart sound. These 13 patients were, therefore, excluded from further consideration, leaving 41 patients in the study group.

When first seen their ages had ranged from 1 week to 64 years and, excluding the deaths, the age range at follow-up was 6 to 71 years. Twenty-eight were male and 13 female, giving the same preponderance of males as is found in isolated aortic stenosis. Seven had previously had a coarctation of the aorta resected.

The evidence for the diagnosis of a bicuspid aortic valve in these 41 patients was as follows:

(A) A bicuspid aortic valve was found at operation or necropsy in 7 patients.

(B) In 27 patients echophonocardiographic studies showed coincidence of the moment of $\overrightarrow{\vec{\theta}}$ halting of the opening aortic valve cusps and the onset of the vibrations of the ejection sound on the $\vec{\omega}$

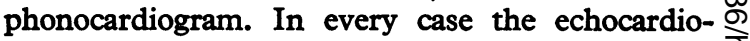
graphic features of a bicuspid aortic valve were also seen. These consisted of either an eccentricity index $\overrightarrow{0}$ greater than 1.25 (Nanda et al., 1974; Radford et al., 0 1976) or, in the apical view, the presence of echoes from the aortic cusps throughout systole (Leec et al., 1978).

(C) In 3 cases, the technical quality of the echo recordings was poor, and in 4 more, echo studies $\mathbb{D}$ were not performed. In these 7 patients, the diagnosis of a bicuspid aortic valve rests on the finding of an aortic ejection sound identified by a phonocardiogram with a simultaneous carotid pulse recording.

\section{METHODS}

The investigations carried out on the patients in this study were as follows:

(1) Careful review of the clinical history, the relation of the ejection sound on the original phonocardiograms to the carotid pulse tracing, and the original electrocardiogram and chest $x$-ray film (Fig. 1).

(2) A clinical examination, electrocardiogram and chest $x$-ray were performed on all the living patients. In patients in whom the echocardiogram or the lateral chest $x$-ray film suggested that there might be calcium in the aortic valve, $x$-ray screening with image amplification was carried out to determine the presence or quantity of calcification.

(3) A standard echocardiographic study.

(4) In order to determine whether or not the 'ejection sound' originated from the aortic valve 오 simultaneous phonocardiogram and echocardiograms were recorded at $200 \mathrm{~mm} / \mathrm{s}$ (Leech et al., 1978). Particular attention was paid to the moments of $N$ aortic valve opening and tricuspid valve closure.

(5) External carotid pulse tracings were recorded 0 and the 'T-time', or time to half maximal upstroke $\mathrm{\omega}$ excursion (Epstein and Coulshed, 1964) and the left ventricular ejection time (Weissler et al., 1968) were measured.

\section{Results}

The findings in 41 patients are summarised in Table 1. The minimal duration of follow-up was 5 years the longest being 25 years, the mean 10.9 years and the median 11 years. 
Table 1 Results of follow-up of 41 patients initially presenting with signs of a non-stenotic bicuspid aortic valve: minimum follow-up period was 5 years, with the exception of 2 patients in whom the diagnosis was confirmed at necropsy

\begin{tabular}{|c|c|c|c|c|c|c|c|c|}
\hline \multirow{2}{*}{$\begin{array}{l}\text { Case } \\
\text { no. }\end{array}$} & \multirow{2}{*}{$\begin{array}{l}\text { Age at } \\
\text { final } \\
\text { examination } \\
(y)\end{array}$} & \multirow{2}{*}{$\begin{array}{l}\text { Age } \\
\text { first seen }\end{array}$} & \multirow[t]{2}{*}{ Sex } & \multirow{2}{*}{$\begin{array}{l}\text { Years } \\
\text { followed up }\end{array}$} & \multicolumn{4}{|c|}{ Developments during follow-up period } \\
\hline & & & & & Stenosis & Calcium & $B E$ & Regurgitation \\
\hline 1 & 6 & $1 / 52$ & $\mathbf{M}$ & 6 & & & & \\
\hline 2 & 9 & 4 & $\mathbf{M}$ & 5 & & & & \\
\hline 3 & 14 & 5 & $\mathbf{F}$ & 9 & & & & \\
\hline 4 & 15 & 5 & $\mathbf{M}$ & 10 & & & & \\
\hline 5 & 15 & 8 & $\mathbf{F}$ & 7 & + & & & \\
\hline 6 & 15 & 4 & $\mathbf{F}$ & 11 & & & & \\
\hline 7 & 15 & 5 & $\mathbf{M}$ & 10 & & & & \\
\hline 8 & 15 & 8 & $\mathbf{M}$ & 7 & & & & \\
\hline 9 & 16 & 4 & $\mathbf{M}$ & 12 & & & & \\
\hline 10 & 16 & 5 & $\mathbf{F}$ & 11 & & & & \\
\hline 11 & 16 & 6 & $\mathbf{M}$ & 10 & & & & \\
\hline 12 & 16 & 1 & $\mathbf{F}$ & 15 & + & & & \\
\hline 13 & 18 & 12 & $\mathbf{F}$ & 6 & & & & \\
\hline 14 & 18 & 6 & $\mathbf{F}$ & 12 & & & & \\
\hline 15 & 20 & 13 & $\mathbf{F}$ & 7 & & & & \\
\hline 16 & $29 \star$ & 24 & $\mathbf{F}$ & 5 & & & + & \\
\hline 17 & 22 & 15 & $\mathbf{F}$ & 7 & & & & \\
\hline 18 & 22 & 6 & $\mathbf{M}$ & 16 & & & & \\
\hline 19 & 23 & 7 & F & 16 & & & & \\
\hline 20 & 25 & 18 & $\mathbf{F}$ & 7 & & & & \\
\hline 21 & 29 & 14 & $\mathbf{M}$ & 15 & & & & + \\
\hline 22 & 32 & 19 & F & 13 & & & & \\
\hline 23 & 37 & 29 & $M$ & 8 & & & & \\
\hline 24 & 37 & 23 & $\mathbf{M}$ & 14 & & & & \\
\hline 25 & 37 & 28 & $\mathbf{M}$ & 9 & & & + & ++ \\
\hline 26 & $39 *$ & 28 & F & 11 & & & + & +++ \\
\hline 27 & 39 & 30 & $\mathbf{M}$ & 9 & & & & \\
\hline 28 & 45 & 34 & $\mathbf{M}$ & 11 & & & & + \\
\hline 29 & 46 & 38 & $\mathbf{F}$ & 8 & + & + & & + \\
\hline 30 & 47 & 36 & $\mathbf{M}$ & 11 & & & & \\
\hline 31 & 50 * & 49 & $\mathbf{M}$ & $3 / 12$ & & & & \\
\hline 32 & 52 & 41 & $M$ & 11 & + & + & & \\
\hline 33 & 53 & 28 & $\mathbf{M}$ & 25 & & & & \\
\hline 34 & $55 t$ & 40 & $\mathbf{M}$ & 15 & +++ & +++ & & \\
\hline 35 & 54 & 37 & $\mathbf{M}$ & 17 & & & & \\
\hline 36 & $57^{\star}$ & 46 & $M$ & 11 & & & & \\
\hline 37 & $60 *$ & 57 & $\mathbf{M}$ & 3 & & + & & \\
\hline 38 & 62 & 50 & $\mathbf{M}$ & 12 & & & & \\
\hline 39 & 63 & 47 & $M$ & 16 & & & & \\
\hline 40 & $64 t$ & 49 & $\mathbf{M}$ & 15 & $++t$ & +++ & & \\
\hline 41 & 71 & 64 & $\mathbf{M}$ & 7 & + & + & & + \\
\hline
\end{tabular}

$\star$ Death.

†Valve replacement for severe stenosis.

+ , slight; ++ , moderate; +++ severe.

$\mathrm{BE}$, bacterial endocarditis.

Table 2 Details of 5 patients who died during follow-up, in 4 of whom the diagnosis of bicuspid aortic valve was confirmed at necropsy

\begin{tabular}{|c|c|c|c|}
\hline Case no. & Age & Cause of death & State of aortic valve \\
\hline 26 & 39 & Bacterial endocarditis & $\begin{array}{l}\text { Bicuspid, non-stenotic } \\
\text { bacterial endocarditis }\end{array}$ \\
\hline $\begin{array}{l}16 \\
31 \\
36\end{array}$ & $\begin{array}{l}29 \\
50 \\
57\end{array}$ & $\begin{array}{l}\text { Drug overdose } \\
\text { Myocardial infarction } \\
\text { CVA }\end{array}$ & $\begin{array}{l}\text { Unknown } \\
\text { Bicuspid, non-stenotic } \\
\text { Bicuspid, non-stenotic }\end{array}$ \\
\hline 37 & 60 & $\begin{array}{l}\text { Ischaemic heart } \\
\text { disease }\end{array}$ & $\begin{array}{l}\text { Bicuspid, non-stenotic } \\
\text { minimal calcification }\end{array}$ \\
\hline
\end{tabular}

CVA, cerebrovascular accident.

1. DEATHS

Five patients died during the follow-up period (Table 2). In 3 patients (cases 31, 36, and 37) the clinical diagnosis of a bicuspid aortic valve was confirmed at necropsy, the cause of death being unrelated to the valve abnormality. In no case was there significant obstruction to left ventricular outflow. Though case 37 had slight calcification of the aortic cusps, cardiac catheterisation 3 years before death had shown no gradient across the valve. Case 22 had had bacterial endocarditis with trivial aortic regurgitation, but post-mortem information about the valve was not available; death was the result of a drug overdose.

The fifth patient (case 26) who died aged 39 having been followed clinically for 11 years, was the only one in whom the cause of death was related to a bicuspid aortic valve. When she was first seen, a diagnosis of Streptococcus viridans endocarditis was made and an isolated aortic ejection sound was recorded. She was successfully treated with penicillin and subsequently noted to have trivial 


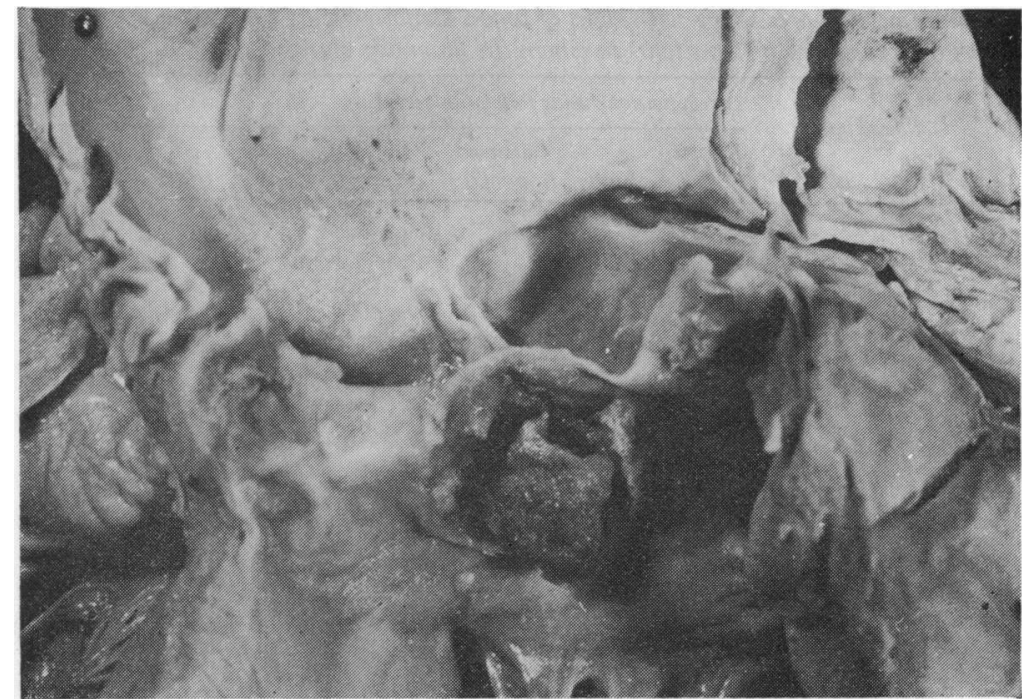

Fig. 2 Aortic valve of case 26 whose death was related to bacterial endocarditis on a bicuspid aortic valve. The single commissure can be seen, with a large vegetation beneath the cusps, embolisation from which was probably the cause of death.

aortic regurgitation. Despite penicillin prophylaxis, she suffered a second attack of Streptococcus viridans endocarditis 4 years later. Treatment with penicillin was again successful, but she was left with clinical signs of severe aortic regurgitation, declined further investigation and treatment, and died suddenly, probably from a cerebral embolus. A large friable calcified vegetation was found on the aortic valve (Fig. 2), but unfortunately examination of the brain was refused.

(2) BACTERIAL ENDOCARDITIS

Three of the patients developed bacterial endocarditis on the aortic valve during the follow-up period, the infecting organism in each case being Streptococcus viridans. None had gross dental sepsis or had undergone any recent dental procedure. Two of them had a second episode of infection, again unrelated to a dental procedure. As a result, one patient was left with severe aortic regurgitation and subsequently died, as described above. Of the other 2 patients, one has moderately severe aortic regurgitation and the other patient only slight regurgitation.

\section{(3) SEVERE AORTIC STENOSIS}

Two of the male patients developed aortic stenosis necessitating valve replacement. The first was 40 years old when first seen, and had an aortic ejection sound with a soft systolic murmur, normal carotid pulse, and normal electrocardiogram. Twelve years later, the ejection sound had disappeared, and he had developed a loud systolic murmur (Fig. 3). The $x$-ray film showed gross calcification of the aortic valve and the electrocardiogram showed left ven- tricular hypertrophy; there was a pressure gradient of $70 \mathrm{mmHg}(9.3 \mathrm{kPa})$ across the valve. At operation aged 52 a calcified bicuspid aortic valve was found and was successfully replaced.

The second patient was 49 when first seen in 1960. The aortic ejection sound was accompanied by a soft ejection systolic murmur, but the electrocardiogram was normal and no valve calcification was apparent on the $x$-ray film. By 1974, there was clinical evidence of severe aortic stenosis, the ejection sound had disappeared, and a peak pressure gradient of $100 \mathrm{mmHg}(13.3 \mathrm{kPa})$, was measured across the valve. At operation, when the patient was 64 , the valve was found to be heavily calcified and bicuspid (Fig. 4), and was replaced.

\section{(4) (a) MILD AORTIC STENOSIS}

Four patients have developed mild aortic stenosis over a period of 7 to 15 years. Though the electrocardiogram remains normal there has been an increase in the intensity of the murmur, slowing of the carotid pulse upstroke, and lengthening of left ventricular ejection time and T-time. In the 2 patients over 30 , these changes have been accompanied by radiological and echocardiographic evidence of valve calcification. In the 2 under 30 , there is no evidence of calcification (Table 3 ).

(4) (b) MILD AORTIC REGURGITATION

The appearance of an early diastolic murmur at the left sternal edge indicates the development of slight aortic regurgitation in 3 patients in whom there has been no evidence of bacterial endocarditis. One of these patients (case 29) also has mild stenosis. Another required mitral valve replacement for 


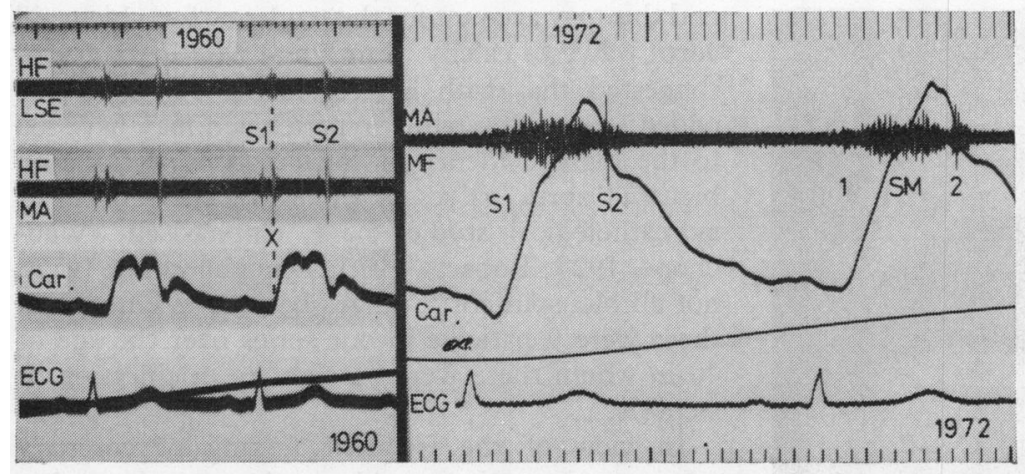

Fig. 3 Phonocardiograms of case 34. On the left is the recording made in 1960 showing the aortic ejection sound $(x)$, with no systolic murmur and a normal carotid pulse. By 1972 the ejection sound had disappeared, a loud ejection systolic murmur was present, and the carotid upstroke was slow. At operation the valve was shown to be heavily calcified and bicuspid.

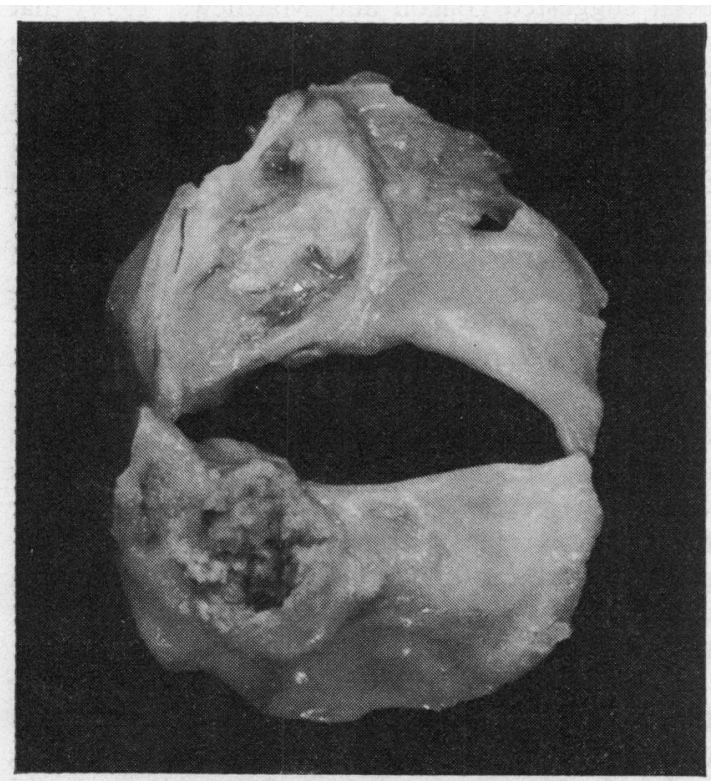

Fig. 4 The aortic valve of case 40, replaced at age 64, When first seen, he had an isolated aortic ejection sound. Fifteen years later, he had signs of severe aortic stenosis and the peak pressure gradient across the valve was $100 \mathrm{mmHg}$ $(13 \cdot 3 \mathrm{kPa})$. The valve is heavily calcified and bicuspid.

Table 3 Development of aortic stenosis and valve calcification in relation to age of the patient

\begin{tabular}{|c|c|c|}
\hline Condition of aortic valve & $\begin{array}{l}\text { Patients under } \\
30 \text { years } \\
\text { (total } 21)\end{array}$ & $\begin{array}{l}\text { Patients over } \\
30 \text { years } \\
\text { (total 20) }\end{array}$ \\
\hline No stenosis & 19 & 14 \\
\hline $\begin{array}{l}\text { Mild stenosis without } \\
\text { calcification }\end{array}$ & 2 & 0 \\
\hline $\begin{array}{l}\text { Mild calcification } \\
\text { without significant }\end{array}$ & 0 & 1 \\
\hline $\begin{array}{l}\text { Mild stenosis with } \\
\text { calcification }\end{array}$ & 0 & 3 \\
\hline $\begin{array}{l}\text { Aortic valve replacement } \\
\text { for severe calcific aortic } \\
\text { stenosis }\end{array}$ & 0 & 2 \\
\hline
\end{tabular}

severe mitral regurgitation caused by bacterial endocarditis on a floppy mitral valve. At operation the aortic valve was found to be bicuspid and because of the slight regurgitation was replaced (Fig. 5).

(5) NO CLINICAL CHANGE

In the remaining 26 patients, the original clinical finding of an aortic ejection sound without any other signs of aortic stenosis has not changed (Fig. 5 Seventeen are less than 30 years of age and their mean follow-up is 10.0 years. The mean follow-up of the 9 patients who are over 30 is 13.9 years.

\section{Discussion}

As a result of an interest in ejection sounds (Leatham and Vogelpoel, 1954) and the observation that they occasionally occur in 'normal' children (Leatham et al., 1963), it was speculated that an isolated aortic ejection sound might indicate the presence of a non-stenotic bicuspid aortic valve. Patients in whom an isolated aortic ejection sound had been recorded phonocardiographically were, therefore, followed up, and the survivors were investigated using echophonocardiography. Using the criteria which have been developed for the non-invasive diagnosis of a bicuspid aortic valve (Leech et al., 1978), confirmation of the original clinical diagnosis was obtained in 41 patients. In every instance where direct examination of the valve at necropsy (4 cases) or surgery ( 3 cases) has been possible, the diagnosis of a bicuspid aortic valve has been confirmed.

We are thus able to report a follow-up of from 5 to 25 years (mean 10.9 years) in a group of 41 subjects with evidence of an uncomplicated bicuspid aortic valve at the first examination (Table 1). One has died as a result of bacterial endocarditis; 2 have developed calcific aortic stenosis requiring valve replacement; 3 have had bacterial endocarditis which led to significant aortic regurgitation in 2 . There are 4 instances of the development of mild 


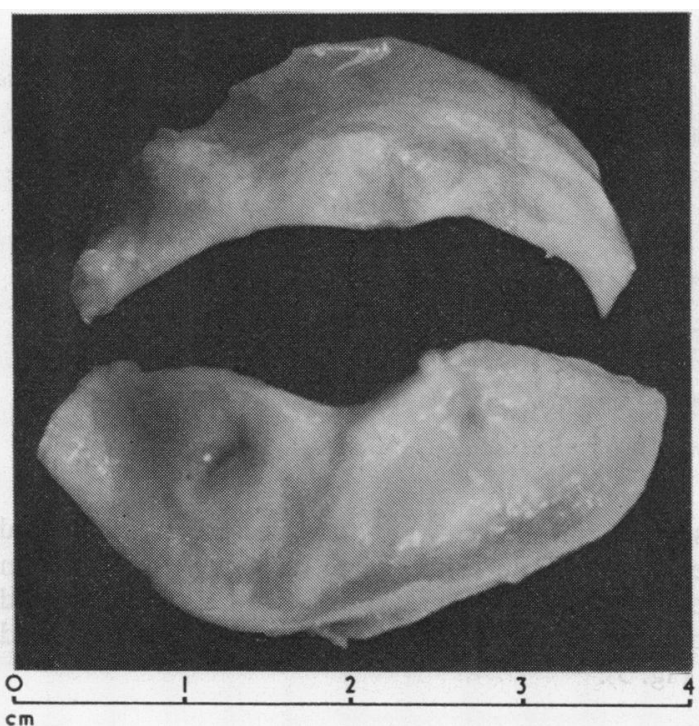

Fig. 5 The aortic valve removed surgically from case 41 at age 71. There is minimal calcification in the bases of the cusps. Peak gradient at catheterisation was $12 \mathrm{mmHg}$ $(1.5 \mathrm{kPa})$.

aortic stenosis and 3 of slight regurgitation unrelated to infection. In 26 subjects, the signs of an uncomplicated bicuspid aortic valve have not altered, and they remain asymptomatic. One of these is now 53 years old and has been followed for 25 years.

The 2 patients requiring valve replacement developed severe calcific aortic stenosis at the ages of 54 and 64 years, indicating that calcification, severity of aortic stenosis, and increasing age are closely interrelated. The severity of the stenosis appears to have progressed relatively rapidly once calcium appeared. Paget (1844) suggested that bicuspid aortic or pulmonary valves 'are very liable to disease'. Because of their configuration, the free edges of the cusps of such valves are subjected to increased stress during systole (Edwards, 1961), and this may account for the tendency for a bicuspid aortic valve to calcify. Smith and Matthews (1955) suggested that with coarctation of the aorta the added stress of systemic hypertension may have led to the high incidence of calcific aortic stenosis on bicuspid aortic valves in these patients. However, as pathological studies have emphasised (Wauchope, 1928; Roberts, 1970; Fenoglio et al., 1977), not all bicuspid aortic valves become calcified, and there were 9 patients in our series over the age of 40 in whom there were no signs of calcification or stenosis.

In view of the frequent finding of coronary atheroma in patients with aortic stenosis, it has been suggested (Bacon and Matthews, 1959) that the atheromatous state causing the coronary disease is also responsible for aortic cusp stiffening. The results of the present study do not provide evidence to support this concept. Two of our patients died of coronary disease; one had, in addition, widespread severe atheroma of his iliac and femoral vessels requiring surgical treatment, but only minimal deposition of calcium in the aortic valve cusps; the other had a normally functioning bicuspid valve. Moreover, atherosclerosis is a disorder of the endothelium and intima of the arterial wall, whereas calcification and stiffening of a bicuspid valve starts in the cusp fibrosa, as it does in a tricuspid aortic valve at a greater age (aortic sclerosis). Thus our findings are more suggestive of a premature ageing process as the cause of calcification and stenosis on a congenitally abnormal valve, rather than this being the result of an atheromatous diathesis.

Calcification on a bicuspid aortic valve is rare before the age of 30 (Campbell, 1968). In our series only 2 patients developed stenosis before this age, and in both cases the degree of stenosis was mild and was not associated with calcium (Table 3 ). This contrasts with the natural history of patients who have a congenitally stenotic valve when they are first seen, since haemodynamic studies (Cohen et al., 1972; El Said et al., 1972) have shown that

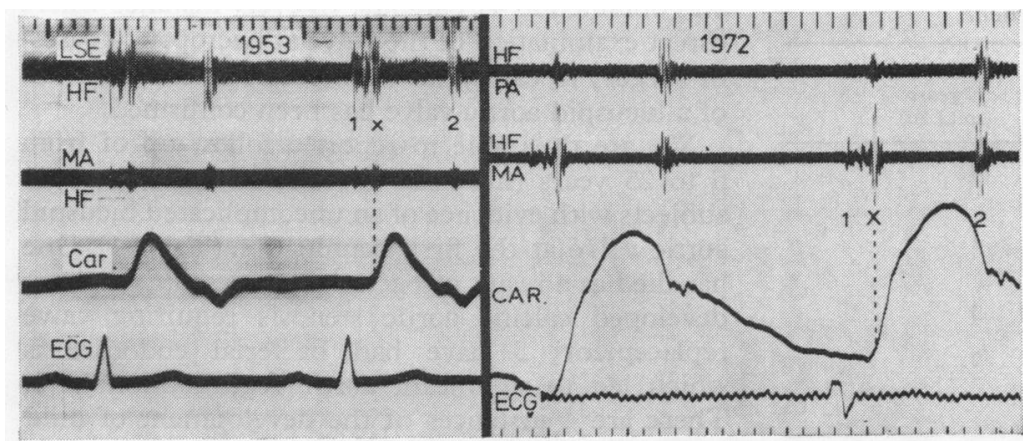

Fig. 6 Phonocardiograms of case 33 taken in 1953 and 1972. The only abnormality is the lone aortic ejection sound which remains unchanged over a follow-up period of 25 years. 
in many of these patients the severity of the stenosis tends to increase. With the exception of those patients who developed bacterial endocarditis, aortic regurgitation was not an important complication, occurring to a mild degree in only 3 cases. Significant aortic regurgitation may present with a bicuspid valve but it is likely that the regurgitation is long standing, and therefore such patients would not have been included in our study group.

The present study confirms the susceptibility of a bicuspid aortic valve to bacterial endocarditis which occurred in 3 patients. Two patients suffered a second episode. Endocarditis was responsible for the only valve-related death in our series. Thefinding of an isolated aortic ejection sound is, therefore, an indication for antibiotic prophylaxis before dental treatment or other procedures likely to produce bacteraemia. It may even be significant in planning contraception in view of the report by De Swiet et al. (1975) of endocarditis on a bicuspid aortic valve after insertion of an intrauterine contraceptive device.

It is reassuring to find no detectable change in 26 of the 41 patients ( $63 \%$ ), followed up for a mean of 11.3 years, including 7 out of the 10 patients over the age of 50 .

Deterioration caused by the development of calcific aortic stenosis is most unlikely before the age of 40 and so, apart from the risk of bacterial endocarditis against which precautions can be taken, a young person found to have an isolated aortic ejection sound can be assured of a good prognosis for at least 25 years. At present we see older patients every 3 years, increasing the frequency of follow-up if calcification of the aortic valve is detected.

Continued follow-up of the patients reported here will be required before the precise incidence of severe aortic stenosis on a previously non-stenotic bicuspid aortic valve can be determined.

We are grateful to the British Heart Foundation who supported Graham Leech as a Senior Research Fellow and Peter Mills as a Junior Research Fellow.

\section{References}

Bacon, A. P. C., and Matthews, M. B. (1959). Congenital bicuspid aortic valves and the aetiology of isolated aortic valvular stenosis. Quarterly fournal of Medicine, 28, 545-560.

Bonner, A. J., Jr., Sacks, H. N., and Tavel, M. E. (1973). Assessing the severity of aortic stenosis by phonocardiography and external pulse recordings. Circulation, 48, 247-252.

Campbell, M. (1968). Calcific aortic stenosis and congenital bicuspid aortic valves. British Heart fournal, 30, 606-616.

Campbell, M., and Kauntze, R. (1953). Congenital aortic valvular stenosis. British Heart fournal, 15, 179-194.

Cohen, L., Friedman, W., and Braunwald, E. (1972). Natural history of mild congenital aortic stenosis elucidated by serial hemodynamic studies. American fournal of Cardiology, 30, 1-5.

De Swiet, M., Ramsay, I., and Rees, G. (1975). Bacterial endocarditis after insertion of intra-uterine contraceptive device. British Medical fournal, 3, 76-77.

Edwards, J. E. (1961). The congenital bicuspid aortic valve. Circulation, 23, 485-488.

El Said, G., Galioto, F. M., Jr., Mullins, C. E., and McNamara, D. G. (1972). Natural hemodynamic history of congenital aortic stenosis in childhood. American fournal of Cardiology, 30, 6-12.

Epstein, E. J., and Coulshed, N. (1964). Assessment of aortic stenosis from the external carotid pulse wave. British Heart fournal, 26, 84-96.

Fenoglio, J. J., Jr., McAllister, H. A., Jr., DeCastro, C. M., Davia, J. E., and Cheitlin, M. D. (1977). Congenital bicuspid aortic valve after age 20. American fournal of Cardiology, 39, 164-169.

Karsner, H. T., and Koletsky, S. (1947). Calcific Disease of the Aortic Valve. Lippencott, Philadelphia.

Leatham, A., Segal, B., and Shafter, H. (1963). Auscultatory and phonocardiographic findings in healthy children with systolic murmurs. British Heart fournal, 25, 451-459.

Leatham, A., and Vogelpoel, L. (1954). The early systolic sound in dilatation of the pulmonary artery. British Heart Fournal, 16, 21-33.

Leech, G.. Mills, P., and Leatham, A. (1978). The diagnosis of a non-stenotic bicuspid aortic valve. British Heart fournal, 40, 941-950.

Lewis, T., and Grant, R. T. (1923). Observations relating to subacute infective endocarditis. I. Notes on the normal structure of the aortic valve. 2. Bicuspid aortic valves of congenital origin. 3. Bicuspid aortic valves in subacute infective endocarditis. Heart, 10, 21-99.

Nanda, N. C., Gramiak, R., Manning, J., Mahoney, E. B., Lipchik, E. O., and DeWeese, J. A. (1974). Echocardiographic recognition of the congenital bicuspid aortic valve. Circulation, $49,870-875$.

Osler, W. (1886). The bicuspid condition of the aortic valves. Transactions of the Association of American Physicians, 1, 185-192.

Paget, J. (1844). On obstructions of the branches of the pulmonary artery. Transactions of the Royal MedicoChirurgical Society, 162-188.

Peacock, T. (1868). Very great contraction of the aortic orifice from disease of the valves. Transactions of the Pathological Society of London, 19, 163-166.

Pomerance, A., and Davies, M. (1975). Pathology of the Heart. Blackwell, Oxford.

Radford, D. J., Bloom, K. R., Izukawa, T., Moes, C. A. F., and Rowe, R. D. (1976). Echocardiographic assessment of bicuspid aortic valves; angiographic and pathological correlates. Circulation, 53, 80-85.

Roberts, W. (1970). The congenitally bicuspid aortic valve. American fournal of Cardiology, 26, 72-83.

Smith, D. E., and Matthews, M. (1955). Aortic valvular stenosis with coarctation of the aorta, with special reference to the development of aortic stenosis upon congenital bicuspid valves. British Heart fournal, 17, 198-206.

Wauchope, G. M. (1928). The clinical importance of variations in the number of cusps forming the aortic and pulmonary valves. Quarterly fournal of Medicine, 21, 383-399.

Weissler, A. M., Harris, W. S., and Schoenfeld, C. D. (1968). Systolic time intervals in heart failure in man. Circulation, 37, 149-159.

Requests for reprints to Dr Peter Mills, Cardiac Department, St George's Hospital, Hyde Park Corner, London SW1X 7EZ. 